\title{
cme Practice Parameter: Medical Treatment of Infantile Spasms \\ Report of the American Academy of Neurology and the Child Neurology Society
}

\author{
M.T. Mackay, MBBS; S.K. Weiss, MD; T. Adams-Webber, MLS; S. Ashwal, MD; D. Stephens, MSc; \\ K. Ballaban-Gill, MD; T.Z. Baram, MD, PhD; M. Duchowny, MD; D. Hirtz, MD; J.M. Pellock, MD; \\ W.D. Shields, MD; S. Shinnar, MD, PhD; E. Wyllie, MD; and O.C. Snead III, MD
}

\begin{abstract}
Objective: To determine the current best practice for treatment of infantile spasms in children. Methods: Database searches of MEDLINE from 1966 and EMBASE from 1980 and searches of reference lists of retrieved articles were performed. Inclusion criteria were the documented presence of infantile spasms and hypsarrhythmia. Outcome measures included complete cessation of spasms, resolution of hypsarrhythmia, relapse rate, developmental outcome, and presence or absence of epilepsy or an epileptiform EEG. One hundred fifty-nine articles were selected for detailed review. Recommendations were based on a four-tiered classification scheme. Results: Adrenocorticotropic hormone (ACTH) is probably effective for the short-term treatment of infantile spasms, but there is insufficient evidence to recommend the optimum dosage and duration of treatment. There is insufficient evidence to determine whether oral corticosteroids are effective. Vigabatrin is possibly effective for the short-term treatment of infantile spasm and is possibly also effective for children with tuberous sclerosis. Concerns about retinal toxicity suggest that serial ophthalmologic screening is required in patients on vigabatrin; however, the data are insufficient to make recommendations regarding the frequency or type of screening. There is insufficient evidence to recommend any other treatment of infantile spasms. There is insufficient evidence to conclude that successful treatment of infantile spasms improves the long-term prognosis. Conclusions: ACTH is probably an effective agent in the short-term treatment of infantile spasms. Vigabatrin is possibly effective.
\end{abstract}

NEUROLOGY 2004;62:1668-1681

West syndrome ${ }^{1}$ is a unique, age-specific epilepsy of early infancy. Infantile spasms are distinct from myoclonic and tonic seizures. ${ }^{2}$ They are characterized by an initial contraction phase followed by a more sustained tonic phase. They can be divided into three types (flexor, extensor, and mixed flexor-extensor spasms), and they can also be asymmetrical. ${ }^{2}$ The EEG characteristically demonstrates hypsarrhythmia, and onset of spasms is frequently associated with neurodevelopmental regression. The incidence of infantile spasms is

Approved by the Quality Standards Subcommittee on July 26, 2003. Approved by the AAN Practice Committee on November 16, 2003. Approved by the AAN Board of Directors in January, 2004. This practice parameter has been endorsed by the American Epilepsy Society.

From the Royal Children's Hospital (Dr. Mackay), Victoria, Australia; Hospital for Sick Children (Drs. Weiss and Snead, T. Adams-Webber and D. Stephens)

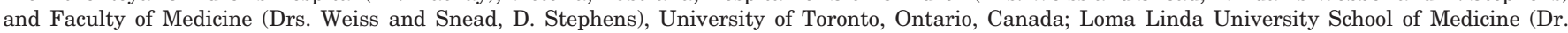
Ashwal), CA; Montefiore Medical Center (Drs. Ballaban-Gill and Shinnar), Albert Einstein College of Medicine, New York; University of California at Irvine

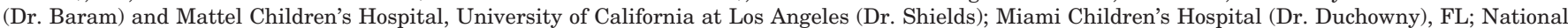

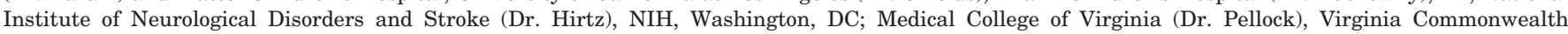
University, Richmond; and Cleveland Clinic Foundation (Dr. Wyllie), OH.

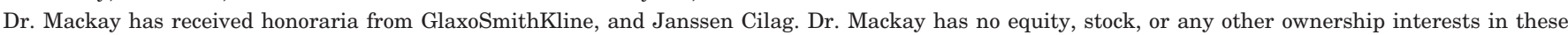
companies. Dr. Pellock has received grants/research support in excess of $\$ 10,000$ and is a paid consultant for Abbott Laboratories, Aventis, Carter Wallace

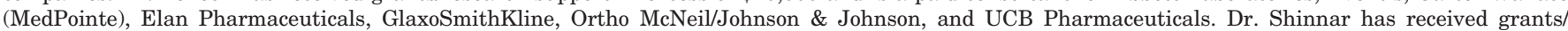
research support from Abbott Laboratories, Elan Pharmaceuticals, and Xcel Pharmaceuticals. He is a paid consultant for Abbott Laboratories, Cephalon, Inc., Elan Pharmaceuticals, Ovation, Pfizer Laboratories, and Xcel Pharmaceuticals. He also has received honoraria from Abbott Laboratories, Cephalon, Inc., Elan Pharmaceuticals, Pfizer Inc., the R.W. Johnson Pharmaceutical Research Institute, UCB Pharmaceuticals, Inc., and Xcel Pharmaceuticals. Dr. Shinnar has no equity, stock, or any other ownership interest in any of these companies. Dr. Shields participated in a study of vigabatrin that was partially supported by an unrestricted grant from Aventis.

Supported in part by the Bloorview Children's Hospital Foundation.

Received September 3, 2003. Accepted in final form March 17, 2004

Address correspondence and reprint requests to the Quality Standards Subcommittee of the American Academy of Neurology, 1080 Montreal Avenue, St. Paul, MN 55116

1668 Copyright (C) 2004 by AAN Enterprises, Inc 
estimated at between 0.25 and 0.60 per 1,000 live births, ${ }^{3-5}$ and the prevalence rate is 0.15 to 0.2 per 1,000 children age 10 or younger. ${ }^{6}$

Two large surveys were performed independently by the Child Neurology Societies in the United States and in Japan to determine the drug of choice for the treatment of infantile spasms. In the American survey, which primarily included US child neurologists, $88 \%$ of respondents used adrenocorticotropic hormone (ACTH) as initial therapy, the most frequently used regimen was a dosage of 40 IU/day for 1 to 2 months, and the choice of drug was not influenced by etiology. ${ }^{7}$ In the Japanese survey, treatment was influenced by etiology, and the order of drug selection was pyridoxine, valproate, and then synthetic ACTH at much lower doses than used in the United States. ${ }^{8}$ In a smaller survey of pediatric neurologists in the United Kingdom, the initial choice was influenced by etiology, and vigabatrin was the most frequently used first-line agent. ${ }^{9}$

Because of these different approaches to the treatment of children with infantile spasms, a practice parameter is warranted to develop evidence-based recommendations for the treatment of this disorder but is constrained by a number of factors. First, there is a paucity of prospective studies and even fewer randomized or controlled treatment trials in this disorder. In addition, published outcome measures are poorly described, are short term, vary from study to study, and are based on small numbers of patients because of the infrequent occurrence of the disorder. Finally, the agents used, dosage regimens, and treatment duration vary from study to study. Specific clinical questions include the following:

1. What are the most effective therapies for infantile spasms as determined by short-term outcome measures including complete cessation of spasms, resolution of hypsarrhythmia, and likelihood of relapse following initial response?

2. How safe are currently used treatments, and do they differ in their tolerability and frequency or severity of side effects?

3. Does successful treatment of infantile spasms lead to long-term improvement of neurodevelopmental outcome or a decreased incidence of epilepsy?

Description of process. The OVID interface was used to search both MEDLINE (1966 to May 2002) and EMBASE (1980 to May 2002) databases simultaneously. The search term "spasms, infantile" retrieved a total of 2,616 references. A text word search was also used to identify other potentially relevant studies. Terms used included the following: infant: spasm, hypsarrhythmia, hypsarrhythmi, cryptogen: infant: spasm, jackknife seizure, nodding spasm, salaam seizure, spasmus nutans, symptomatic infant: spasm, west syndrome:, lightning attack, salaam attack and blitznicksalaamkrampfe, petit mal quadrette, massive myoclon: spasm, and minor motor epilepsy. The wildcard symbol ":" was used to truncate words, allowing retrieval of articles that used variations in word endings. The combined MEDLINE and EMBASE text word searches identified 1,175 articles. All search titles and abstracts were analyzed for content. English language articles on therapy, prognosis, and side effects were selected, including original and review articles. There were 159 articles chosen for detailed review, and individual committee members reviewed, abstracted, and classified these articles to assess the quality of evidence-based data related to study design and treatment effect.

Articles included for analysis required the following: 1) A clearly stated diagnosis of infantile spasms. 2) An EEG demonstrating hypsarrhythmia or modified hypsarrhythmia. Hypsarrhythmia is defined as very high voltage random slow waves and spikes in all cortical areas. The spikes vary from moment to moment in duration and location. ${ }^{10}$ Modified hypsarrhythmia includes variations such as hypsarrhythmia with increased synchronization, asymmetrical hypsarrhythmia, hypsarrhythmia with a consistent focus of abnormal discharge, hypsarrhythmia with episodes of attenuation, and hypsarrhythmia with little sharp wave activity or spike activity. ${ }^{11}$ Articles using a routine EEG recording were acceptable for inclusion because very few articles used video-EEG monitoring. 3) Age of 1 month to 3 years. Infantile spasms were classified as either symptomatic or cryptogenic as defined by the International League Against Epilepsy. ${ }^{12}$ The symptomatic group is characterized by "previous existence of brain damage signs (psychomotor retardation, neurologic signs, radiologic signs, or other types of seizures) or by a known etiology." The symptomatic group can be further divided into prenatal, perinatal, and postnatal groups. Prenatal causes include chromosomal abnormalities, inborn errors of metabolism, neurocutaneous syndromes, cortical malformations, and intrauterine infections. Perinatal causes include hypoxic ischemic encephalopathy and birth trauma. Postnatal causes include CNS trauma, infection, and intracranial hemorrhage. ${ }^{3}$ The smaller cryptogenic group is characterized by "a lack of previous signs of brain damage or of known etiology." Cases described as idiopathic or "doubtful" and post immunization were included in the cryptogenic group for analysis.

Outcome measures included short- and long-term measures. Short-term outcome measures were defined as 1) complete cessation of spasms, 2) resolution of hypsarrhythmia and, where documented, normalization of EEG, and 3) relapse rate. Adverse effects and mortality were documented. In studies with a mean follow-up of $>2$ years, long-term outcome measures were 1) nonepileptiform EEG, 2) absence of seizures, and 3) normal development. Stringent criteria were not used in the analysis of the developmental outcome data because the results of developmental assessments were often based on clinical impression, developmental screening tools, and school placement rather than standardized, age- 


\begin{tabular}{|c|c|c|c|c|c|c|}
\hline Ref. & $\mathrm{n}$ & Class & Type of ACTH (dose) & $\begin{array}{l}\text { No. wk of } \\
\text { full dose }\end{array}$ & Total Rx, wk & $\begin{array}{c}\text { Other } \\
\mathrm{Rx}\end{array}$ \\
\hline 18 & 59 & I/III* & $\mathrm{N}$ & 3 & 12 & No \\
\hline High dose & & & $\mathrm{N}\left(150 \mathrm{IU} / \mathrm{m}^{2}\right)$ & 3 & 12 & No \\
\hline Low dose & & & $\mathrm{N}\left(20 \mathrm{IU} / \mathrm{m}^{2}\right)$ & 3 & 12 & No \\
\hline \multirow[t]{2}{*}{16} & 15 & I/III* & $\mathrm{N}\left(150 \mathrm{IU} / \mathrm{m}^{2}\right)$ & 2 & 4 & No \\
\hline & 14 & & Prednisone (2 mg/kg/d) & 2 & 4 & No \\
\hline \multirow[t]{2}{*}{$17 \ddagger$} & 12 & II & $\mathrm{N}\left(20 \mathrm{IU} / \mathrm{m}^{2}\right)$ & 6 & 7 & No \\
\hline & 12 & & Prednisone (2 mg/kg/d) & & & No \\
\hline 20 & 25 & III & $\mathrm{S} \S$ & 6 & 6 & Yes \\
\hline Low dose & 12 & & (0.2 IU/kg) & $2-4$ & $4-6$ & Yes \\
\hline High dose & 13 & & (1.0 IU/kg) & $4-6$ & $4-6$ & Yes \\
\hline \multirow[t]{2}{*}{$19 \ddagger$} & 19 & III & $\mathrm{S}(10 \mathrm{IU} / \mathrm{d})$ & 5.7 & 5.7 & No \\
\hline & 23 & & VGB (100-150 mg/kg/d) & 5.7 & 5.7 & No \\
\hline 21 & 5 & III & $\mathrm{N}(20-40 \mathrm{IU})$ & NS & $6-10$ & No \\
\hline $23^{* *}$ & & III & $\mathrm{N}$ & Var & Var & NS \\
\hline SIS & 69 & & $\mathrm{~N}\left(110 \mathrm{IU} / \mathrm{m}^{2}\right)$ & 3 & 8 & NS \\
\hline CIS & 36 & & $\mathrm{~N}\left(110 \mathrm{IU} / \mathrm{m}^{2}\right)$ & 3 & 8 & NS \\
\hline CIS & 37 & & ACTH, prednisolone & $8,14-20$ & Var & NS \\
\hline 24 & 15 & IV & $\mathrm{N}\left(150 \mathrm{IU} / \mathrm{m}^{2}\right)$ & 1 & 12 & Yes \\
\hline 22 & 18 & IV & ACTH, $1-24(0.8 \mathrm{mg} / \mathrm{kg})$ & 4 & 6 & Yes \\
\hline
\end{tabular}

* The studies by Hrachovy et al. ${ }^{18}$ and Baram et al. ${ }^{16}$ are considered class I studies when one is comparing high-dose vs low-dose ACTH or ACTH vs prednisone but class III studies when considering whether either medication was effective in decreasing the number of infantile spasms because neither study contained a placebo-controlled group.

$\dagger$ Total of 42 adverse events.

$\ddagger$ Results prior to crossover (phase I).

$\S$ Progressive dosage regimen starting at $0.2 \mathrm{IU} / \mathrm{kg}$ and increasing to $1.0 \mathrm{IU} / \mathrm{kg}$.

$\|$ No statistically significant difference between etiologic subgroups.

II After crossover (at the end of phase II).

\# $p \leq 0.02$ compared to prednisone group.

** Short-term outcome at 10 mo. Numbers of patients differ in Methods and Results.

$\dagger \dagger$ Results combined for ACTH alone and ACTH plus PNL treatment groups in CIS patients.

$\mathrm{ACTH}=$ adrenocorticotropic hormone; $\mathrm{Rx}=$ treatments; F/U = follow-up; SIS = symptomatic infantile spasm; CIS = cryptogenic infantile spasm; $\mathrm{N}=$ natural; $\mathrm{NS}=$ not stated; $\mathrm{RH}=$ reversal of hypsarrhythmia; HPT = hypertension; Irrit = irritability; $\mathrm{S}=$ synthetic; Sed = sedation; VGB = vigabatrin; $\mathrm{CN}=$ completely normal; Var = variable; Hypo- $\mathrm{K}^{+}=$hypokalemia; Pneum = pneumonia.

appropriate psychometric testing. There are very limited natural history data on infantile spasms. Thus, it is impossible to accurately quantify, but at least some children do spontaneously remit, approximately in the order of 10 to $25 \%$ according to older and uncontrolled reports. ${ }^{13-15}$ Data recorded included description of the number of patients entering and completing the trial, age at onset of spasms, age at entry into the study, sex, etiology, drug dosage, duration of therapy, cointerventions, and duration of follow-up.

For the purposes of this practice parameter, we did not consider studies of children with LennoxGastaut syndrome, an epilepsy syndrome of early childhood that frequently follows infantile spasms. Studies were excluded if the patient's age was $<1$ or $>36$ months at the time of entry into the study or if an EEG was not performed to confirm the diagnosis of hypsarrhythmia or modified hypsarrhythmia. Ret- rospective studies were excluded if they were single case reports or case series with fewer than four infants. Studies on long-term prognosis that were uncontrolled for treatment, letters, abstracts, and unpublished data were also excluded.

A four-tiered classification scheme for diagnostic evidence recently approved by the Quality Standards Subcommittee was utilized as part of this assessment (Appendix 1). Depending on the strength of this evidence, it was decided whether specific recommendations could be made and, if so, the strength of these recommendations (Appendix 2). Evidence pertinent to each treatment together with the committee's evidence-based recommendations is presented.

ACTH and oral corticosteroids. Is ACTH effective in the treatment of infantile spasms? Evidence. Fourteen studies met the inclusion criteria for analysis. Five were randomized controlled studies, one 


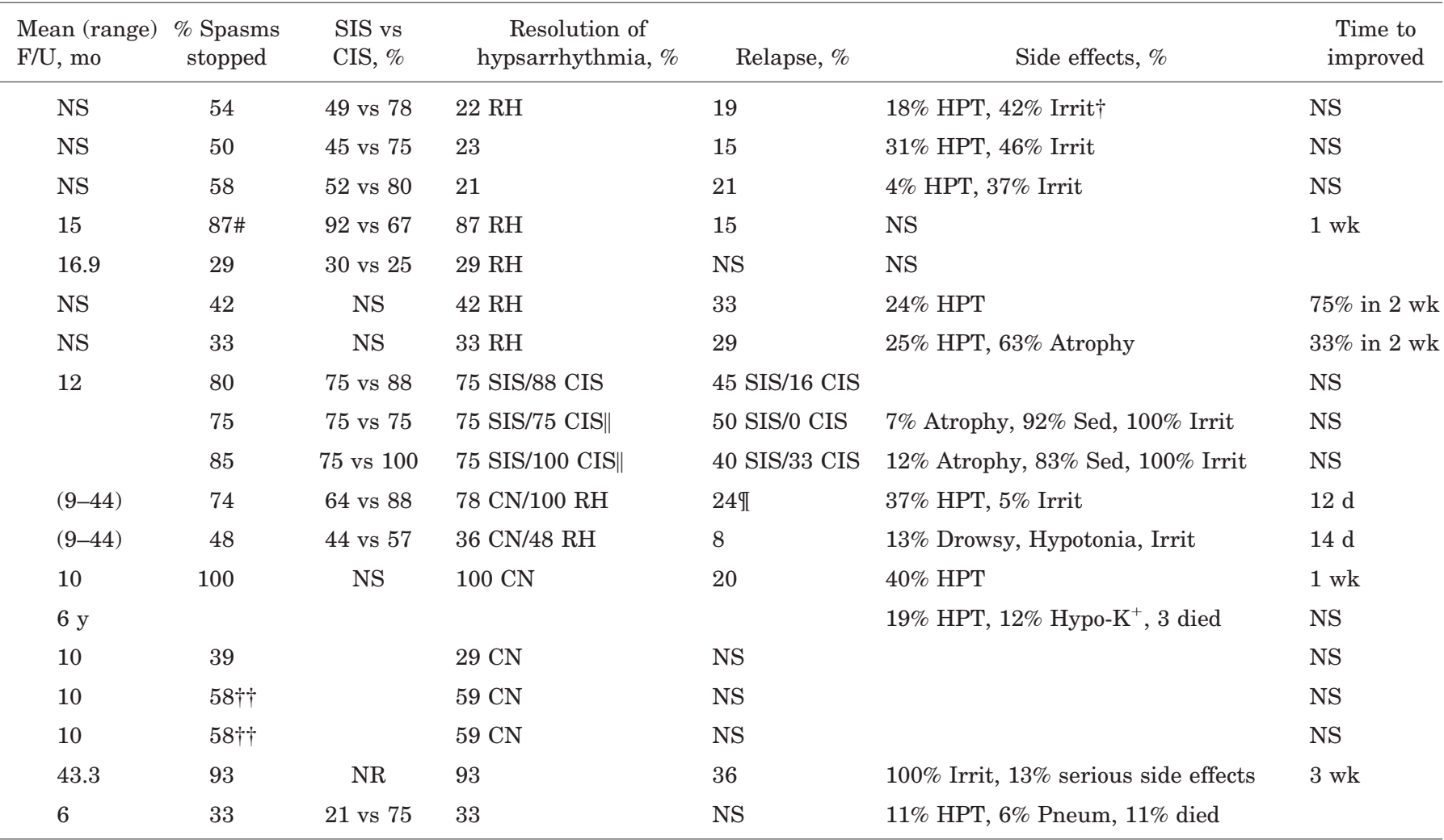

providing class I, one providing class II, and three providing class III evidence ${ }^{16-20}$; four were prospective open-label trials providing class III and class IV evidence $^{21-24}$ (table 1); and five were retrospective case series, also providing class IV evidence ${ }^{25-29}$ (table 2). Only one class II study was placebo controlled, ${ }^{17}$ and two were crossover studies using prednisone (class II) ${ }^{17}$ or vigabatrin (class III). ${ }^{19}$ Age at onset of spasms ranged from 1 week to 24 months, and age at entry into the study ranged from 1 to 34 months. All trials used video-EEG monitoring to document a treatment response. Two studies used synthetic ACTH, ${ }^{19,20}$ and one used ACTH fragments. ${ }^{22}$ ACTH dosage varied from $0.2 \mathrm{IU} / \mathrm{kg}$ up to $150 \mathrm{IU} / \mathrm{m}^{2}$, and duration of treatment at the highest dose ranged from 1 to 6 weeks, with total treatment time varying from 4 to 12 weeks. All studies but one involved small numbers (5 to 59) of patients, and only two were stratified at entry into cryptogenic and symptomatic groups.

In the randomized controlled trials, cessation of spasms was reported in $87 \%$ of patients in one class I study, ${ }^{16} 42 \%$ of patients in one class II study, ${ }^{17}$ and 54 to $80 \%$ of patients in three class III studies. ${ }^{18-20}$ Time from initiation of treatment to cessation of spasms as stated in three studies was 7 to 12 days. In all randomized controlled trials except one, ${ }^{16}$ a greater percentage of cryptogenic patients responded to ACTH. The class I study ${ }^{16}$ reported a response rate of $87 \%$ using high-dose ACTH therapy, whereas the class II study ${ }^{17}$ achieved a response rate of $42 \%$ using low-dose and short-duration ACTH therapy.
Two class III studies found no dose-related difference in the response rate of infantile spasms to ACTH therapy. ${ }^{18,20}$ The relapse rate was $15 \%$ in the class I study, ${ }^{16} 33 \%$ in the class II study, ${ }^{17}$ and 19 to $24 \%$ in class III studies. ${ }^{18-20}$

There were four open-label prospective studies of ACTH treatment of infantile spasms: Two were class III cohort studies, ${ }^{21,23}$ and two others were class IV. ${ }^{22,24}$ All 5 children responded to low-dose ACTH in one class III study, ${ }^{21}$ whereas one class IV study reported a $93 \%$ response rate in 15 children treated with high-dose therapy. Relapse rates were $20^{21}$ and $36 \%$, respectively. ${ }^{24}$ One class III study compared the efficacy of synthetic ACTH with oral corticosteroids and benzodiazepines. ${ }^{23}$ This study was stratified for symptomatic/cryptogenic etiology. In the 69 symptomatic patients treated with ACTH, 39\% had cessation of spasms, and EEG normalized in 29\%. Analysis of comparative efficacy between ACTH and prednisone was not possible in the cryptogenic group because the short-term responses to ACTH and to ACTH followed by prednisolone were combined into one treatment group. Use of ACTH fragments resulted in cessation of spasms in $33 \%$ of patients. ${ }^{22}$

The majority of studies on the use of ACTH in infantile spasms are retrospective. Five studies meeting selection criteria were analyzed, providing class IV evidence with numbers ranging from 25 to 166 children $^{25-29}$ (see table 2). Response rates for cessation of spasms ranged from 59 to $100 \%$ and resolution of hypsarrhythmia from 57 to $97 \%$, but relapse rates ranged from 9 to $62 \%$. 


\begin{tabular}{|c|c|c|c|c|c|c|}
\hline Ref. & $\mathrm{n}$ & Class & $\begin{array}{c}\text { Type of ACTH } \\
\text { (dose) }\end{array}$ & $\begin{array}{l}\text { No. wk of } \\
\text { full dose }\end{array}$ & Total Rx, wk & Other $\mathrm{Rx}$ \\
\hline 25 & 25 & IV & N (110 IU) & 2.1 & NS & No \\
\hline \multirow[t]{3}{*}{26} & $22 \mathrm{TS}$ & IV & $\begin{array}{l}\mathrm{N}(20-140 \mathrm{IU}) \text { or } \\
\quad \mathrm{S}(0.2-1.2 \mathrm{mg})\end{array}$ & 6 & 6 & NS \\
\hline & 25 CIS & & & NS & NS & NS \\
\hline & 119 SIS & & & NS & NS & NS \\
\hline 27 & 26 & IV & $\mathrm{N}\left(40-129 \mathrm{IU} / \mathrm{m}^{2}\right)$ & $2-25$ & $4.5-44$ & NS \\
\hline 28 & 30 & IV & $\mathrm{N}\left(150 \mathrm{IU} / \mathrm{m}^{2}\right)$ & 1 & 12 & NS \\
\hline 29 & 55 & IV & N (80 IU alt) & 2 & $6-14$ & Yes \\
\hline Early, $<1$ mo & 31 & & & & & \\
\hline Late & 24 & & & & & \\
\hline
\end{tabular}

\footnotetext{
* Discontinued because of side effects.

$\dagger p<0.002$.
}

$\mathrm{ACTH}=$ adrenocorticotropic hormone; $\mathrm{Rx}=$ treatments; F/U = follow-up; SIS = symptomatic infantile spasm; CIS = cryptogenic infantile spasm; $\mathrm{N}=$ natural; $\mathrm{NS}=$ not stated; TS = tuberous sclerosis; $\mathrm{S}=$ synthetic; $\mathrm{NR}=$ not relevant; HPT $=$ hypertension; $\mathrm{CM}=$ cardiomyopathy; $\mathrm{CN}=$ completely normal; alt = alternate days; Pneum $=$ pneumonia.

Are oral corticosteroids effective in the treatment trials of infantile spasms? Evidence. Five studies were analyzed, with numbers ranging from 12 to 39 children: two randomized controlled studies providing class II and III evidence, ${ }^{16,17}$ two prospective open-label trials (one was a cohort study, the other with patients acting as their own controls) provided class III evidence, ${ }^{23,30}$ and one retrospective case series provided class IV evidence ${ }^{28}$ (table 3 ). Both randomized controlled trials used $2 \mathrm{mg} / \mathrm{kg}$ of prednisone for 4 to 7 weeks, and the response rate was 29 to $33 \%$. In a class III open prospective study, 39 symptomatic and 38 cryptogenic patients who were treated with prednisolone $2 \mathrm{mg} / \mathrm{kg}$, had cessation of spasms in 36 and $39 \%$ of cases, respectively. ${ }^{23}$ The EEG normalized in $28 \%$ of symptomatic patients and $42 \%$ of cryptogenic patients. In these three studies, the response rate using oral prednisone was not different from that which might be expected with no treatment based on limited natural history data, and in none of the studies were the effects of oral steroids compared with those of a placebo group. The class IV study reported cessation of spasms and resolution of hypsarrhythmia in 59\% of children treated with 3 $\mathrm{mg} / \mathrm{kg} /$ day of prednisone. ${ }^{28}$ None of the controlled trials compared differing doses of oral corticosteroids.

Is ACTH more effective than oral corticosteroids in the treatment of infantile spasms? Evidence. Two class I and II randomized controlled trials, ${ }^{16}, 17$ one class III prospective open-label trial, ${ }^{23}$ and one class IV retrospective case study $^{28}$ compared ACTH and prednisone (see tables 1 to 3 ). The class I randomized controlled trial demonstrated superior efficacy of high-dose ACTH therapy, ${ }^{16}$ and the class II study showed no difference in efficacy between low-dose ACTH and prednisone. ${ }^{17}$ High-dose ACTH therapy was superior to prednisone in the class IV study, with cessation of spasms in $100 \%$ of patients treated with ACTH vs 59\% resolution of spasms in the prednisone group. The EEG normalized in $97 \%$ of ACTHtreated patients vs $50 \%$ in the prednisone group. ${ }^{28}$

What are the side effects of ACTH and oral corticosteroids? Evidence. In the five randomized controlled trials, hypertension was reported in 0 to $37 \%$ of patients, ${ }^{17-20}$ irritability in 37 to $100 \%,{ }^{18-20}$ infection in $14 \%,{ }^{18}$ and cerebral atrophy in $62 \%$ of patients in one study. ${ }^{20}$ ACTH was discontinued in 1 of 19 (5\%) patients in one study because of side effects. ${ }^{19}$ There were no deaths. In the two studies comparing highdose vs low-dose ACTH, hypertension ${ }^{18}$ and "cerebral shrinkage" ${ }^{20}$ were more common in patients on highdose ACTH. In the four prospective open-label studies, hypertension was reported in 7 to $40 \%$ of patients, ${ }^{21-24}$ irritability in 85 to $100 \%,{ }^{23,24}$ and infection in $6 \% 22$; ACTH was discontinued in two of five $(40 \%)$ patients in one study because of side effects. ${ }^{21}$ There were 5 deaths in 304 cases $^{22,23}$; in one study, two of three deaths from sepsis were directly attributable to ACTH. ${ }^{23}$

Conclusions. One class I, one class II, and five prospective class III studies demonstrate that ACTH is probably effective in the short-term treatment of infantile spasms and in the resolution of hypsarrhythmia. Time to response is usually within 2 weeks, and an "all-or-none" response has been reported in a number of studies. ${ }^{17,24}$ The data are insufficient to determine the optimum dosage and duration of therapy. One class II and several class III studies showed limited efficacy for the use of oral corticosteroids in infantile spasms $(<40 \%$ resolved) that did not differ substantially from the spontaneous rate of remission based on limited natural history data. ACTH is more effective than oral corticosteroids in causing the cessation of seizures. Side effects reported for ACTH were common and included hypertension, irritability, infection, revers- 
Table 2 Continued

\begin{tabular}{|c|c|c|c|c|c|c|}
\hline Mean F/U, mo & $\begin{array}{c}\text { Cessation of } \\
\text { spasms, no. }(\%)\end{array}$ & $\begin{array}{l}\text { SIS vs CIS, } \\
\text { no. }(\%)\end{array}$ & $\begin{array}{c}\text { Resolution of } \\
\text { hypsarrhythmia, no. (\%) }\end{array}$ & $\begin{array}{l}\text { Relapse, } \\
\%\end{array}$ & Side effects, $\%$ & $\mathrm{D} / \mathrm{C}^{*}$ \\
\hline 26.5 & $14(67)$ & $\begin{array}{l}8(89) \text { vs } 10 \\
(83)\end{array}$ & $12(57)$ & $4(27)$ & 27 & 3 \\
\hline \multirow[t]{3}{*}{98} & $16(73)$ & \multirow[t]{3}{*}{ NR } & NS & $10(62)$ & \multirow[t]{3}{*}{ HPT 45, CM 9} & \\
\hline & $20(80)$ & & NS & $6(30)$ & & \\
\hline & 71 (59) & & NS & $22(31)$ & & \\
\hline 36 & $17(65)$ & NR & $17(65)$ & $2(12)$ & NS & NS \\
\hline 25 & $30(100)$ & NS & 29 (97) CN & $14(47)$ & NS & \\
\hline \multirow[t]{3}{*}{53} & $41(75)$ & NS & NS & $5(9)$ & Pneum 2 & 0 \\
\hline & $27(87) \dagger$ & & & & & \\
\hline & $14(58)$ & & & & & \\
\hline
\end{tabular}

ible cerebral shrinkage, and rarely death due to sepsis.

Recommendations. 1. ACTH is probably effective for the short-term treatment of infantile spasms and in resolution of hypsarrhythmia (level B).

2. There is insufficient evidence to recommend the optimum dosage and duration of treatment with ACTH for the treatment of infantile spasms (level U).

3 . There is insufficient evidence that oral corticosteroids are effective in the treatment of infantile spasms (level U).

Vigabatrin. Is vigabatrin effective in the treatment trials of infantile spasms? Evidence. Fourteen studies met the inclusion criteria for analysis: one randomized placebo controlled study providing class I evidence, ${ }^{31}$ two randomized controlled studies providing class III evidence, ${ }^{19,32}$ six prospective uncontrolled open-label trials, ${ }^{33-38}$ and five retrospective case series, ${ }^{25,39-42}$ providing class IV evidence (table 4). Age at onset ranged from 1 week to 18 months, and age at treatment ranged from 2 to 28 months.

The class I randomized placebo-controlled trial ( $\mathrm{n}=20$ in each group) showed that at the end of the 5 -day double-blind phase, seven (35\%) patients treated with vigabatrin were spasm-free and five (25\%) had resolution of hypsarrhythmia compared with two (10\%) and one (5\%), respectively, in the placebo group ( $p=0.063$ ). Relapse was seen in four (20\%) of vigabatrin-treated patients. Forty-two percent of those who entered the open-label phase were spasm-free. ${ }^{31}$ In one of the larger class III studies $(\mathrm{n}=179), 23 \%$ of patients were spasm-free 2 weeks after commencement of treatment, and this increased to $65 \%$ at the end of a 3-month open-label period. ${ }^{32}$ In the other class III study $(\mathrm{n}=23), 48 \%$ of patients were spasm-free and had resolution of hypsarrhythmia. Twenty-one to $44 \%$ of symptomatic patients responded compared with 27 to $57 \%$ of cryptogenic patients. ${ }^{19,31,32}$ The relapse rate ranged from 8 to $20 \%$ across the three randomized controlled studies. ${ }^{19,31,32}$

In the six class IV open-label uncontrolled pro- spective studies ( $\mathrm{n}=6$ to 116 patients), the response rate ranged from 0 to $59 \%$ for children with symptomatic infantile spasms and from 50 to $100 \%$ for cryptogenic infantile spasms; children with cryptogenic infantile spasms had a higher response rate to vigabatrin than those with symptomatic spasms across all prospective studies. ${ }^{33-38}$

In the nine prospective studies reviewed, vigabatrin dosages ranged from 18 to $200 \mathrm{mg} / \mathrm{kg} /$ day. The numbers were not large enough to determine if the efficacy of vigabatrin in infantile spasms was dose dependent. The time from initiation of therapy to cessation of spasms ranged from 12 to 35 days. In the class I study, 20 children who initially received placebo for 5 days before crossing over to vigabatrin had a similar outcome when compared with the 20 children who received vigabatrin at the beginning of the spasms. The time to EEG response was 7 to 35 days, and 11 to $83 \%$ of children had resolution of hypsarrhythmia. The relapse rate of infantile spasm after initial control ranged from $0 \%$ in one study with seven children with tuberous sclerosis to $29 \%$; however, it is difficult to compare these data because the period of follow-up was widely variable, ranging from 3 months to 6.5 years.

Is vigabatrin effective in the treatment of infantile spasms in children with tuberous sclerosis? Evidence. Seven studies (total $n=45$ ) were identified, providing class III and class IV evidence. Only those prospective studies of children with tuberous sclerosis and infantile spasms who were evaluated under 3 years of age were included. ${ }^{19,32,33,35,36,38,42}$ The response of the infantile spasms to vigabatrin in infants with tuberous sclerosis was uniformly good, with a high percentage of responders whose spasms remitted. Overall cessation of spasms was seen in 41 of 45 $(91 \%)$ of children treated with vigabatrin, with a $100 \%$ response rate seen in five studies..$^{19,32,35,36,38}$

What are the side effects of vigabatrin? Evidence. In the three randomized controlled studies, sedation was noted in 9 to $24 \%$ of patients, ${ }^{19,31,32}$ irritability in 4 to $9 \%,,^{19,31,32}$ and insomnia ${ }^{32}$ and hypotonia ${ }^{19}$ in $9 \%$; 


\begin{tabular}{|c|c|c|c|c|c|c|}
\hline Ref. & $\mathrm{n}$ & Class & Type of steroid (dose) & $\begin{array}{l}\text { Duration of } \\
\text { full dose, wk }\end{array}$ & $\begin{array}{l}\text { Total treatment } \\
\text { duration, wk }\end{array}$ & Other $\mathrm{Rx}$ \\
\hline \multirow[t]{2}{*}{16} & 14 & I/III* & Prednisone (2 mg/kg) & 2 & 4 & No \\
\hline & 15 & & $\mathrm{ACTH}\left(150 \mathrm{IU} / \mathrm{m}^{2}\right)$ & 2 & 4 & No \\
\hline \multirow[t]{2}{*}{$17 \dagger$} & 12 & II & Prednisone (2 mg/kg) & Variable & Variable & No \\
\hline & 12 & & $\mathrm{ACTH}\left(20 \mathrm{IU} / \mathrm{m}^{2}\right)$ & 6 & 7 & No \\
\hline $23 \ddagger$ & & III & Prednisolone (2 mg/kg) & 8 & $20-32$ & NS \\
\hline CIS & 38 & & Prednisolone $(2 \mathrm{mg} / \mathrm{kg})$ & 8 & $20-32$ & NS \\
\hline SIS & 39 & & Prednisolone (2 mg/kg) & 8 & $20-32$ & NS \\
\hline 30 & 12 & III & Prednisone (2 mg/kg) & 6 & 20 & NS \\
\hline 28 & 22 & IV & Prednisone (3 mg/kg) & 4 & 16 & NS \\
\hline
\end{tabular}

* The study by Baram et al. ${ }^{16}$ is considered a class I when comparing ACTH vs prednisone but class III study when considering whether either medication was effective in decreasing the number of infantile spasms because it did not contain a placebo-controlled group.

$\dagger$ Results prior to crossover (phase I).

$\ddagger$ Short-term outcome at 10 mo.

$\mathrm{Rx}=$ treatment; F/U = follow-up; SIS = symptomatic infantile spasms; CIS = cryptogenic infantile spasms; $\mathrm{RH}=$ reversal of hypsarrhythmia; NS = not stated; ACTH = adrenocorticotropic hormone; HPT = hypertension; CN $=$ completely normal.

Table 4 Vigabatrin studies: Short-term results

\begin{tabular}{|c|c|c|c|c|c|c|c|c|}
\hline Ref. & $\mathrm{n}$ & Class & $\begin{array}{l}\text { Dose, } \\
\mathrm{mg} / \mathrm{kg}\end{array}$ & $\begin{array}{l}\text { Other } \\
R x\end{array}$ & $\begin{array}{c}\text { Mean (range) } \\
\text { F/U, mo }\end{array}$ & $\begin{array}{l}\text { Cessation of } \\
\text { spasms, } \\
\text { no. }(\%)\end{array}$ & $\begin{array}{c}\text { Cessation at } \\
\text { later } \mathrm{F} / \mathrm{U}, \\
\text { no. }(\%)\end{array}$ & $\begin{array}{l}\text { SIS vs. CIS, } \\
\text { no. }(\%)\end{array}$ \\
\hline 31 & 40 & $\mathrm{I}$ & 150 & Yes & 5 & $15(42)^{*}$ & & $9(32)$ vs $6(50)$ \\
\hline Placebo & 20 & & & & & $2(10) \dagger$ & & \\
\hline VGB & 20 & & & & & $7(35) \dagger$ & & \\
\hline 32 & 179 & III & & Yes & $(3-24)$ & $32(23) \ddagger$ & $87(65) \ddagger$ & $20(21)$ vs $45(27)$ \\
\hline LD & 90 & & $18-36$ & & & $8(11)$ & NS & \\
\hline HD & 89 & & $100-148$ & & & $24(36)$ & NS & \\
\hline $19 \S$ & 23 & III & $100-150$ & No & $(9-24)$ & $11(48)$ & & $7(44)$ vs $4(57)$ \\
\hline 33 & 116 & IV & $50-200$ & No & 23 & $45(39)$ & & $24(29)$ vs $21(62)$ \\
\hline 34 & 23 & IV & $50-150$ & Yes & 65 & $11(48)$ & $13(72) \dagger \dagger$ & 7 (37) vs $4(100)$ \\
\hline 35 & 29 & IV & $50-125$ & No & 18 & $17(59)$ & & $13(59)$ vs $4(66)$ \\
\hline 36 & 6 & IV & $50-100$ & No & 13 & $4(75)$ & & $1(33)$ vs $3(100)$ \\
\hline 37 & 28 & IV & $75-150$ & No & 20 & $18(57)$ & & $8(47)$ vs $6(55)$ \\
\hline 38 & 42 & IV & $40-150$ & Yes & 10 & $11(26)$ & & 6 (19) vs 5 (50) \\
\hline 25 & 21 & IV & $100-150$ & NS & 21 & $14(67)$ & $11(69)$ & $8(72)$ vs $8(80)$ \\
\hline 39 & 18 & IV & $50-150$ & No & 25 & $9(50)$ & & $4(36)$ vs $5(71)$ \\
\hline 40 & 25 & IV & $60-80$ & NS & 19 & $16(64)$ & & $13(68)$ vs $3(50)$ \\
\hline 41 & 7 & IV & $50-100$ & Yes & NS & $4(57)$ & & $3(75)$ vs $1(50)$ \\
\hline 42 & 250 & IV & $25-400$ & Yes & 8 & $131(68)$ & & $97(75)$ vs $43(69)$ \\
\hline
\end{tabular}

* Following entry to open-label phase.

$\dagger$ At end of double-blind phase.

$\ddagger$ Fifty-two percent of tuberous sclerosis patients were spasm-free and had no hypsarrhythmia 2 wk after starting treatment. The num-

ber of patients seizure-free increased to $87(65 \%)$ at $3 \mathrm{mo}$.

$\S$ Results describe outcome at end of phase I (prior to crossover).

$\|$ Four (36\%) have completely normal EEG.

II At end of phase II (after crossover).

** Cause of death unrelated to treatment.

$\dagger \dagger$ Outcome at 3 mo.

+ Cause of death not stated.

$\mathrm{Rx}=$ treatments; F/U = follow-up; SIS = symptomatic infantile spasm; CIS = cryptogenic spasm; D/C = discontinued because of side effects; VGB = vigabatrin; Sed = sedation; Insom = insomnia; Irrit = irritability/agitation; $\mathrm{LD}=$ low dose; NS = not stated; HD = high dose; $\mathrm{CN}=$ completely normal.

1674 NEUROLOGY 62 May (2 of 2) 2004 
Table 3 Continued

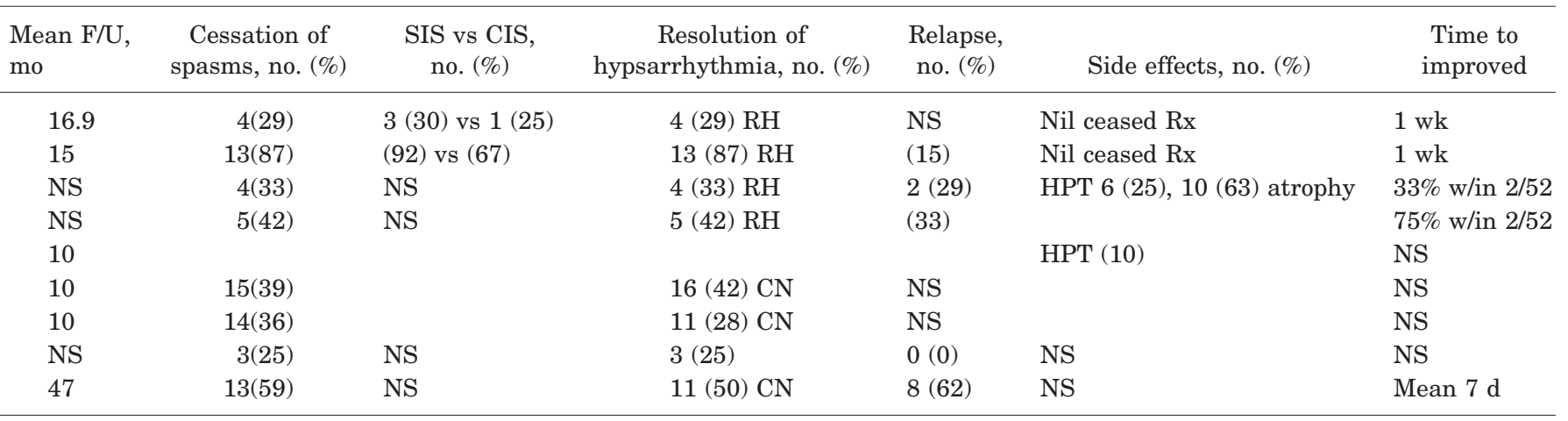

Table 4 Continued

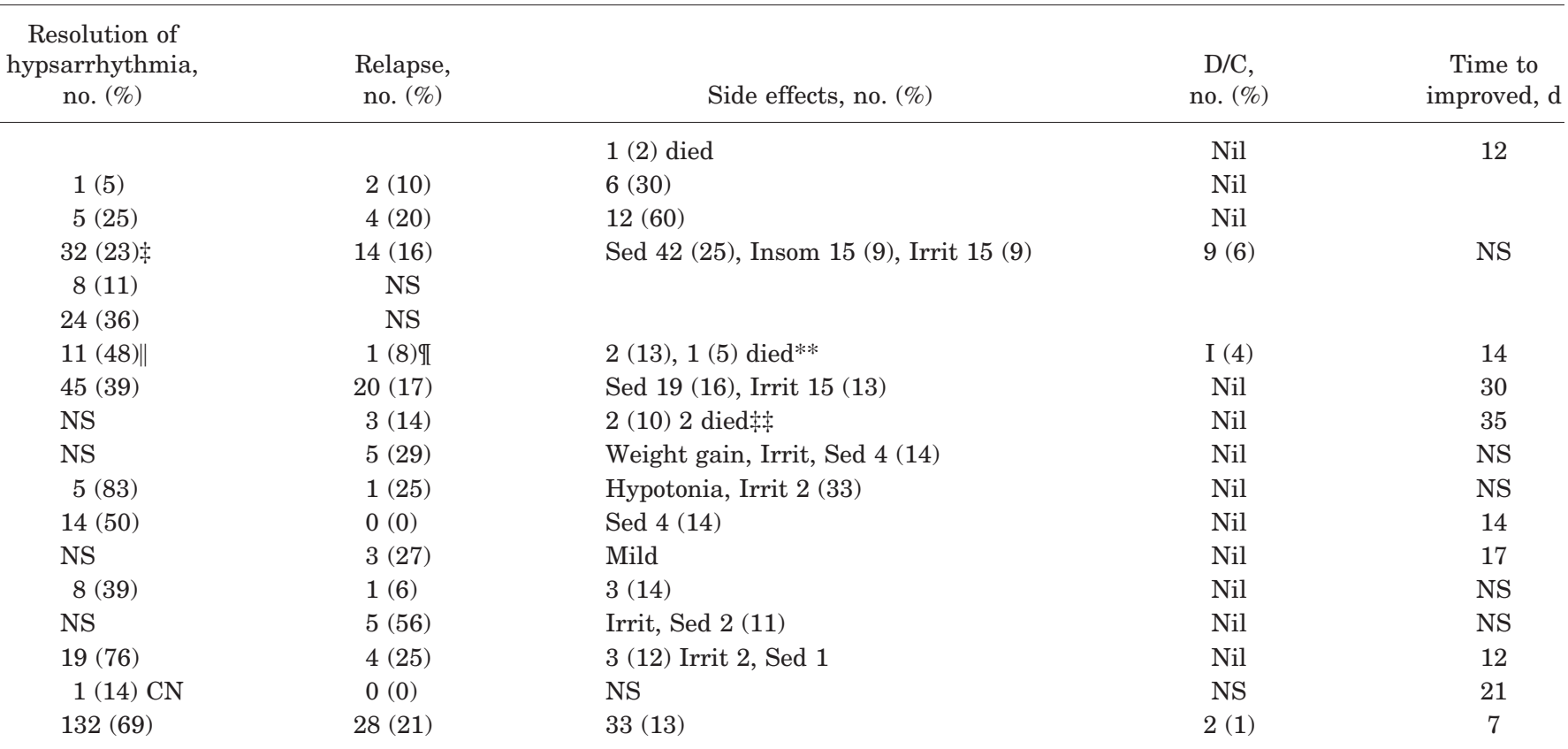


vigabatrin was discontinued in 0 to $6 \%$ of patients because of side effects. ${ }^{19,31,32}$ There were two deaths unrelated to vigabatrin and one death in which the cause was not known across the three studies. ${ }^{19,32}$ In the six class IV open-label uncontrolled prospective studies, sedation was noted in 14 to $16 \%$ of patients, ${ }^{33,35,37}$ irritability in 13 to $33 \%,{ }^{33-36}$ and hypotonia in $33 \% .{ }^{34}$ None of the patients discontinued treatment, and there were no reported deaths in 244 patients across six studies.

The most significant side effect of vigabatrin is the development of concentric visual field defects, which has been reported in 10 to $40 \%$ of adult patients on vigabatrin treatment in uncontrolled case series. ${ }^{44,45}$ This side effect also has been recently reported in children. ${ }^{46,47}$ In one study, 6 of 12 children receiving vigabatrin had visual field defects. Visual field assessment could not be performed in 141 additional children because of age or developmental delay. ${ }^{43}$ Currently, the incidence of visual field deficits in infants under 1 year of age treated with vigabatrin is unknown. However, there is emerging evidence that abnormalities in the electroretinogram may occur in children as a result of vigabatrin therapy. ${ }^{48}$

Is vigabatrin more effective than hormonal agents in the treatment of infantile spasms? Evidence. Two studies that compared vigabatrin with steroids in the treatment of infantile spasms were analyzed: a randomized controlled trial providing class III evidence $^{19}$ and a retrospective case series providing class IV evidence. ${ }^{25}$

Although the vigabatrin doses were similar (100 to $150 \mathrm{mg} / \mathrm{kg} /$ day), either ACTH or hydrocortisone was used in varying doses. In the class III randomized controlled trial, the efficacy, defined as total resolution of spasms at 20 days, was not significantly different $(p=0.12) .{ }^{19}$ In the class IV retrospective study, the drugs were of similar efficacy, but the outcome measure was 12 months spasm-free. In both studies, the rate of EEG improvement was superior for ACTH as compared with vigabatrin, but the relapse rate was higher for ACTH-treated children ( $p$ values not stated). ${ }^{25}$ Side effects were more common in patients treated with corticosteroids (27 to 37\%) compared with 6 to $13 \%$ of patients treated with vigabatrin.

Conclusions. Two class III randomized controlled trials and the majority of class IV studies demonstrated that vigabatrin reduced the occurrence of infantile spasms and was associated with resolution of hypsarrhythmia, but less than half of those treated responded. One small class I study showed the same trend, but the difference was not statistically significant when compared with placebo. Vigabatrin appears to be effective within 14 days of initiation of therapy. A consensus of class III and class IV studies indicated that vigabatrin reduced the occurrence of infantile spasms in the great majority of children with tuberous sclerosis. Vigabatrin is considered by the Food and Drug Administration to be "experimental and unproven" for all indications, and it is not licensed for use in the United States. The potential of vigabatrin for retinal toxicity in children receiving the drug for infantile spasms is a concern, but the magnitude of risk is unknown and therefore cannot be factored into a risk-benefit equation.

Recommendations. 1. Vigabatrin is possibly effective for the short-term treatment of infantile spasms (level C, class III and IV evidence).

2. Vigabatrin is also possibly effective for the short-term treatment of infantile spasms in the majority of children with tuberous sclerosis (level C, class III and IV evidence).

3. Serious concerns about retinal toxicity in adults suggest that serial ophthalmologic screening is required in patients on vigabatrin. However, data are insufficient to make recommendations regarding the frequency or type of screening that would be of value in reducing the prevalence of this complication in children (level U, class IV studies).

Other agents. What other agents have been evaluated for the treatment of infantile spasms? Valproic acid. Two studies met the inclusion criteria for analysis; both were class IV uncontrolled prospective open-label studies. ${ }^{49,50}$ Valproate dose ranged from 25 to $100 \mathrm{mg} / \mathrm{kg} /$ day. One study reported cessation of spasms in $73 \%$ and resolution of hypsarrhythmia in $91 \%$ of 22 children at 6 months' follow-up. ${ }^{50}$ The majority responded within 2 weeks, but $23 \%$ relapsed. Thrombocytopenia occurred in one-third of patients, requiring discontinuation of valproate in four patients. The other study reported cessation of spasms in $72 \%$ of children at 3 months' follow-up. ${ }^{49}$

Nitrazepam. Two class IV retrospective case series met the inclusion criteria for analysis. ${ }^{51,52}$ Dose ranged from 0.5 to $3.5 \mathrm{mg} / \mathrm{kg} /$ day. Cessation of spasms was reported in 3 of $10(30 \%)^{51}$ and 13 of 24 $(54 \%)^{52}$ of children. Resolution of hypsarrhythmia occurred in 11 of $24(46 \%)$ and relapse in 2 of $13(15 \%)$ of children in one study. ${ }^{52}$

Pyridoxine. Pyridoxine has been reported to be the treatment of first choice for infantile spasms in Japan, but there are no randomized controlled trials of this drug. Two uncontrolled prospective open-label trials providing class IV evidence were analyzed..$^{53,54}$ The response rate ranged from 13 to $29 \%$ in these studies. There is no evidence to suggest that the response rate of infantile spasms to pyridoxine therapy exceeds the spontaneous remission rate that would be predicted from limited natural history data.

Newer antiepileptic drugs and novel therapies. Zonisamide, ${ }^{55}$ IV immunoglobulin (IVIG), ${ }^{56}$ liposteroid, ${ }^{57}$ the ketogenic diet, ${ }^{58}$ thyrotropin-releasing hormone (TRH), ${ }^{59}$ and topiramate ${ }^{60,61}$ all have been administered for the treatment of infantile spasms. All except one class III study ${ }^{57}$ provided class IV evidence, either in small uncontrolled prospective open-label studies or in retrospective case series.

Combination therapies. Two small uncontrolled prospective open-label studies used a combination of ACTH and vigabatrin ${ }^{62}$ and hydrocortisone and valproate, ${ }^{63}$ providing class IV evidence. A short-term 
(1-week) response to ACTH plus vigabatrin was seen in all nine patients, with one child relapsing after 9 months. Cessation of spasms was seen in $77 \%$ of 94 children treated with sodium valproate and hydrocortisone within 2 weeks; $81 \%$ of 59 followed to at least age 2 years were seizure-free.

Conclusions. There are insufficient or inadequate data to determine whether valproic acid, nitrazepam, pyridoxine, zonisamide, topiramate, novel therapies (IVIG, liposteroid, ketogenic diet, TRH) or combination therapies are effective in the treatment of infantile spasms.

Recommendations. 1. There is insufficient evidence to recommend other treatments (valproic acid, benzodiazepines, pyridoxine, newer antiepileptic drugs, or other or novel therapies) for the treatment of infantile spasms (level U, class III and IV evidence).

Long-term outcome. Natural history studies. The only available information on the natural history of infantile spasms comes from an evaluation of the pre-ACTH literature, but comparison of treatment studies to natural history controls is constrained by a number of factors. Interpretation of natural history outcomes in infantile spasms that were stratified into cryptogenic and symptomatic patients proved difficult because of limited diagnostic testing in the $1950 \mathrm{~s}$ and $1960 \mathrm{~s}$, particularly in regard to the neuroimaging techniques used at that time. In addition, there were inconsistencies in the literature concerning use of the terms "cryptogenic" and "symptomatic," as previously reviewed.1,12,64 Also, inclusion criteria differed across studies, and assessment of cognitive outcome was based on qualitative assessments including school placement rather than on formal psychometric testing. With these caveats, it is instructive to examine outcome studies of children with infantile spasms in the presteroid era.

Gibbs et al. ${ }^{10}$ in 1954 reported long-term follow-up in 103 survivors over 3 years of age from an original cohort of 237 patients with infantile spasms. Detailed clinical and EEG data were available in 69 children. This cohort can be considered untreated as none received steroids and all drugs used at that time are known to be ineffective against infantile spasms. At age 5 or older, $11 \%$ of the children still had infantile spasms, $45 \%$ had other seizure types, and $55 \%$ were seizure-free. Hypsarrhythmia persisted in $31 \%$, focal EEG abnormalities were noted in $52 \%$, and the EEG was normal in $17 \%$. Only $13 \%$ of children over 1 year of age had normal intellectual development, but the method of assessment was not stated and there was no stratification for cryptogenic and symptomatic groups. Mortality was $11 \%$ before age 2 , but the cause of death was not given.

There also are reports of early, spontaneous remission of infantile spasms. ${ }^{14,65}$ One retrospective study reported spontaneous remission in $11 \%$ of 44 patients treated with metharbital or phenytoin, but not steroids, within 6 months of the onset of spasms and in $25 \%$ by 12 months of onset. ${ }^{14}$ However, it was not stated what percentage of children in this group developed other seizure types. This is an important omission, given the fact that approximately $20 \%$ of children with infantile spasms develop complex conditions such as the Lennox-Gastaut syndrome. The developmental outcome of children in this group was poor, with only $9 \%$ being defined as normal. This outcome was not significantly different when compared with a separate cohort treated with either lowdose ACTH or prednisone. ${ }^{66}$

What is the effect of short-term treatment of infantile spasms on long-term outcome? Evidence. Seven studies provided class III and IV evidence for the long-term outcome of infantile spasms. None was randomized or controlled, five were prospective openlabel studies, ${ }^{23,34,38,63,66}$ and two were retrospective case series ${ }^{67,68}$ (table 5).

One prospective class III study reported long-term follow-up in 64 patients, ${ }^{66} 48$ of whom had previously been entered in randomized crossover treatment protocols. ${ }^{17}$ The other 16 children in this cohort were treated in a prospective open-label protocol of either ACTH or prednisone. ${ }^{21,30}$ Low-dose ACTH (20 IU) and $2 \mathrm{mg} / \mathrm{kg}$ of prednisone were used across the studies, and outcome was analyzed by treatment and etiology. The majority of children (87\%) had symptomatic spasms. Mean duration of follow-up was 50 months, with a range of 9 months to 10 years. There was a 5\% mortality rate in symptomatic patients, but cause of death was not stated. Cryptogenic patients had a better outcome, with 2 of 8 cryptogenic patients being cognitively normal, compared with 1 of the 56 symptomatic patients $(p<0.05)$. Infantile spasms persisted in $42 \%$ of children, whereas $53 \%$ of patients developed other seizure types and $47 \%$ were seizure-free. There was no significant difference in outcome for ACTH treatment compared with prednisone. Delay in initiation of treatment of $>5$ weeks from onset of the spasms had no influence on longterm cognitive outcome or on the development of epilepsy.

In the second prospective class III study, follow-up beyond 6 years was reported in 102 children from an original cohort of 121 cryptogenic cases. ${ }^{23}$ Fifty percent of ACTH-treated patients were developmentally normal, $62 \%$ were seizure-free, and $39 \%$ had a normal EEG. When ACTH was compared with other therapies such as oral steroids, benzodiazepines, or conventional anticonvulsants, there was a significant difference in favor of ACTH for psychometric development and achieving a seizure-free state $(p<0.05)$. An improved neurodevelopmental outcome also was associated with early commencement of therapy of $<1$ month.

One retrospective class IV study compared outcome in children treated with $\mathrm{ACTH}$, vitamin $\mathrm{B}_{6}$, and sodium valproate. Twenty-one percent of ACTH- 


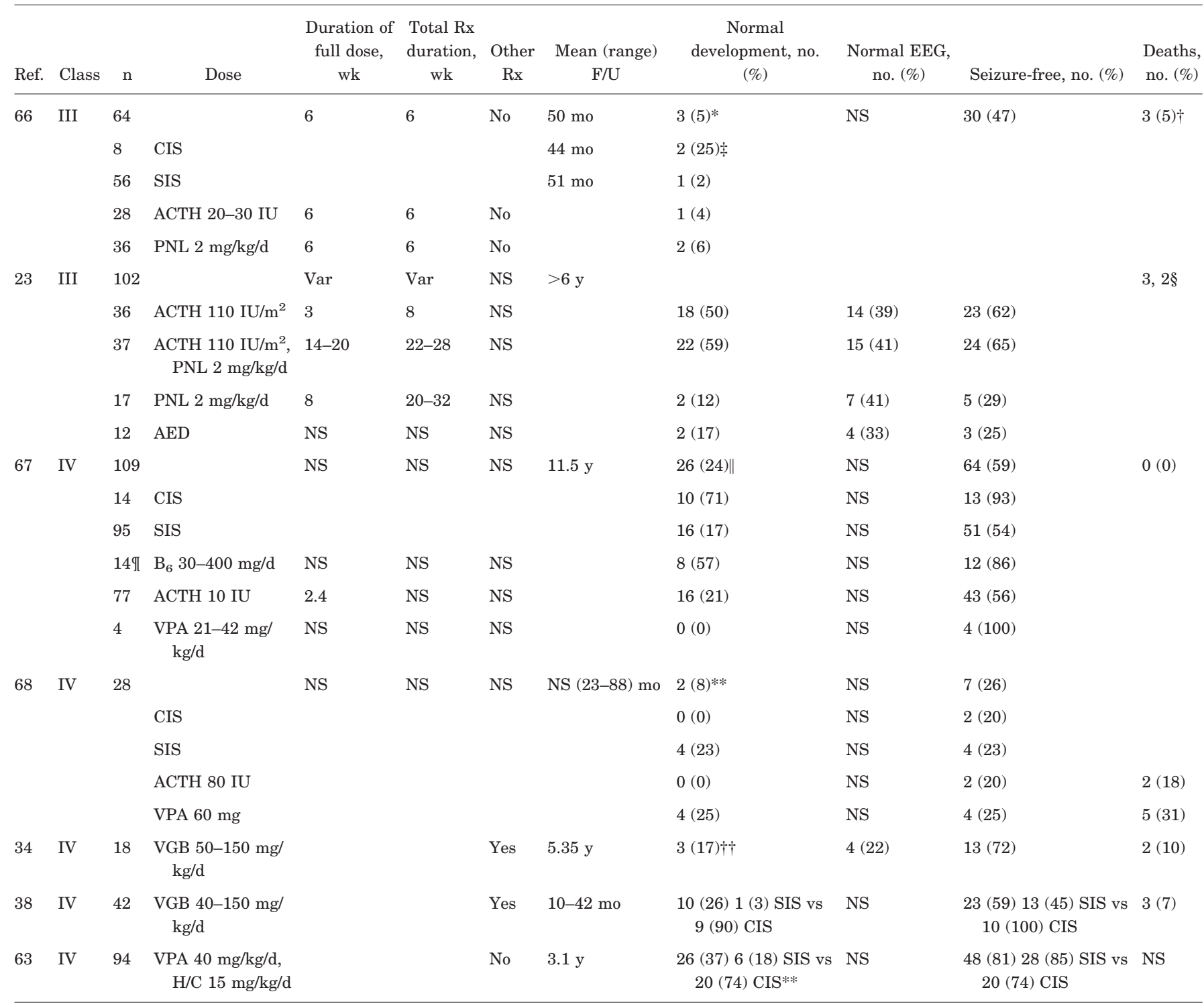

$* \mathrm{I} \mathrm{Q}>80$.

$\dagger$ All symptomatic patients.

$\ddagger p<0.025$ for CIS vs SIS patients.

$\S$ Two deaths secondary to complications of ACTH.

$\|$ Developmental quotient $>75$.

II Only reported long-term outcome in $\mathrm{B}_{6}$-responsive cases.

** I Q $>70$.

$\dagger \dagger$ Normal or slightly delayed.

$\mathrm{Rx}=$ treatment; F/U = follow-up; CIS = cryptogenic infantile spasm; SIS = symptomatic infantile spasm; ACTH = adrenocorticotrophic hormone; $\mathrm{PNL}=$ prednisone; $\mathrm{VGB}=$ vigabatrin; $\mathrm{VPA} / \mathrm{HC}=$ combination of sodium valproate and hydrocortisone; $\mathrm{B}_{6}=$ vitamin $\mathrm{B}_{6} ; \mathrm{AED}=$ antiepileptic drug; NS = not stated; Var = variable.

treated and $57 \%$ of $\mathrm{B}_{6}$-responsive patients had normal cognitive outcome. Fifty-six percent of ACTHtreated and $86 \%$ of $\mathrm{B}_{6}$-responsive patients were seizure-free. None of the valproate-treated patients had normal IQ, but all were seizure-free. ${ }^{67}$ As previously observed in other studies, cryptogenic patients had a better outcome. In contrast, outcome was uniformly poor in another study comparing ACTH and valproate; only $8 \%$ of patients had an IQ over 70 , and $26 \%$ were seizure-free with no significant difference between cryptogenic and symptomatic or ACTH- and valproate-treated patients. Delay in initiation of treatment had no influence on long-term outcome. ${ }^{68}$

Two prospective open-label class IV studies reporting long-term outcome in infants treated with vigabatrin in addition to other medications were identified ${ }^{34,38}$ In one study, $17 \%$ of children were normal or slightly developmentally delayed, and $72 \%$ were seizure-free for at least 1 year. ${ }^{34}$ In the other study, $36 \%$ of children were seizure-free and develop- 
mentally normal. Nine (90\%) of cryptogenic patients had a good developmental outcome compared with one (3\%) symptomatic patient after follow-up from 10 months to 3.5 years. ${ }^{38}$

These studies support that a cryptogenic etiology of infantile spasms is associated with a better longterm outcome. Other factors independent of treatment reported to be associated with a good prognosis include normal development prior to onset of spasms, with no prior neurologic deficit and absence of other seizure types in association with spasms. ${ }^{23,66}$

Conclusions. The evidence is conflicting and limited to class III and IV that treatment of infantile spasms with agents including ACTH, oral corticosteroids, vigabatrin, valproic acid, and pyridoxine improves the long-term prognosis for cognitive outcome or decreases the later incidence of epilepsy.

Recommendations. 1. The data are insufficient to make any recommendations regarding the use of $\mathrm{ACTH}$, corticosteroids, vigabatrin, valproic acid, and pyridoxine to improve the long-term outcomes (seizure freedom and normal development) of children with infantile spasms (level U, class III and IV evidence).

2. The data are insufficient to conclude that early initiation of treatment should be used to improve the long-term outcome of children with infantile spasms (level U, class III and IV evidence).

\section{Future research}

1. Further prospective randomized masked controlled studies are required to determine the optimal treatment of children with infantile spasms, with the following features included:

a. Studies should be stratified at entry for etiology, and inclusion criteria should include infantile spasms and the presence of either classic or modified hypsarrhythmia. The infantile spasms and EEG should be confirmed by video-EEG monitoring.

b. A standardized pretreatment developmental assessment is necessary to enable longitudinal evaluation of cognitive outcome.

c. A standard dose and duration of treatment are essential to allow statistical comparison of short- and long-term outcomes across centers.

d. Short-term measures should be precisely defined and should include complete cessation of spasms as well as a grading of the EEG response to include resolution of hypsarrhythmia, residual epileptiform activity, or complete normalization.

e. Long-term measures also should be well defined and should include cognitive outcomes using standardized psychometric assessments. The long-term incidence of epilepsy should also be determined.
2. There is a need for the development of an animal model to investigate mechanisms of epileptogenesis in infantile spasms and identify novel targets for therapeutic development

3. Efficacy of newer anticonvulsants should specifically be assessed, based on a knowledge of their mechanisms of action.

Disclaimer. This statement is provided as an educational service of the American Academy of Neurology (AAN). It is based on an assessment of current scientific and clinical information. It is not intended to include all possible proper methods of care for a particular neurologic problem or all legitimate criteria for choosing to use a specific procedure. Neither is it intended to exclude any reasonable alternative methodologies. The AAN recognizes that specific patient care decisions are the prerogative of the patient and the physician caring for the patient, based on all of the circumstances involved.

\section{Appendix 1: American Academy of Neurology evidence classification scheme for a therapeutic article}

Class I: evidence provided by a prospective, randomized, controlled clinical trial with masked outcome assessment, in a representative population.

The following are required: (a) Primary outcome(s) is/are clearly defined; (b) exclusion/inclusion criteria are clearly defined; (c) adequate accounting for dropouts and crossovers with numbers sufficiently low to have minimal potential for bias; and (d) relevant baseline characteristics are presented and substantially equivalent among treatment groups or there is appropriate statistical adjustment for differences.

Class II: evidence provided by a prospective matched group cohort study in a representative population with masked outcome assessment that meets a-d above or a randomized control trial in a representative population that lacks one criteria of $\mathrm{a}-\mathrm{d}$.

Class III: all other controlled trials (including well-defined natural history controls or patients serving as own controls) in a representative population, where outcome assessment is independent of patient treatment.

Class IV: evidence from uncontrolled studies, case series, case reports, or expert opinion

\section{Appendix 2: American Academy of Neurology system for translation of evidence to recommendations}

Translation of evidence to recommendations

Rating of recommendation

Level A rating requires at least one convincing class I study or at least two consistent, convincing class II studies.

Level B rating requires at least one convincing class II study or at least three consistent class III studies.

Level $\mathrm{C}$ rating requires at least two convincing and consistent class III studies.

A = established as effective, ineffective or harmful for the given condition in the specified population.

$\mathrm{B}=$ probably effective, ineffective, or harmful (or probably useful/predictive or not useful/predictive) for the given condition in the specified population.

$\mathrm{C}=$ possibly effective, ineffective, or harmful (or possibly useful/predictive or not useful/predictive) for the given condition in the specified population.

$\mathrm{U}=$ data inadequate or conflicting. Given current knowledge, treatment is unproven. 


\section{Appendix 3: Quality Standards Subcommittee Members}

Gary Franklin, MD, MPH (co-chair); Gary Gronseth, MD (co-chair); Charles E. Argoff, MD; Stephen Ashwal, MD (ex-officio); Christopher Bever, Jr., MD; Jody Corey-Bloom, MD, PhD; John D. England, MD; Jacqueline French, MD (ex-officio); Gary H. Friday, MD; Michael Glantz, MD; Deborah Hirtz, MD; Donald J. Iverson, MD; Samuel Wiebe, MD; and William J. Weiner, MD, Catherine Zahn, MD (ex-officio).

\section{Appendix 4: Child Neurology Society Practice Committee}

Carmela Tardo, MD (chair); Bruce Cohen, MD (vice-chair); Elias Chalhub, MD; Roy Elterman, MD; Murray Engel, MD; Bhuwan Garg, MD; Brian Grabert, MD; Annette Grefe, MD; Michael Goldstein, MD; David Griesemer, MD; Betty Koo, MD; Edward Kovnar, MD; Leslie Ann Morrison, MD Colette Parker, MD; Ben Renfroe, MD; Michael Shevell, MD; Shlomo Shinnar, MD; Gerald Silverboard, MD; Russell Snyder, MD; Dean Timmons, MD; and Greg Yim, MD.

\section{References}

1. Holmes GL, Vigevano F. Epilepsy: a comprehensive textbook. New York: Lippincott-Raven, 1997.

2. Fusco L, Vigevano F. Ictal clinical electroencephalographic findings of spasms in West syndrome. Epilepsia 1993;34:671-678.

3. Cowan LD, Hudson LS. The epidemiology and natural history of infantile spasms. J Child Neurol 1991;6:355-364.

4. Sidenvall R, Eeg-Olofsson O. Epidemiology of infantile spasms in Sweden. Epilepsia 1995;36:572-574.

5. Riikonen R, Donner M. Incidence and aetiology of infantile spasms from 1960-1976: a population study in Finland. Dev Med Child Neurol 1979 21:333-343.

6. Cowan LD, Bodensteiner JB. Prevalence of the epilepsies in children and adolescents. Epilepsia 1989;30:94-106

7. Bobele GB, Bodensteiner JB. The treatment of infantile spasms by child neurologists. J Child Neurol 1994;9:432-435.

8. Ito M, Seki T, Takuma Y. Current therapy for West syndrome in Japan J Child Neurol 2000;15:424-428.

9. Appleton RE. The treatment of infantile spasms by paediatric neurologists in the UK and Ireland. Dev Med Child Neurol 1996;38:278-279.

10. Gibbs EL, Anderson EM, Gibbs FA. Diagnosis and prognosis of hypsarrhythmia and infantile spasms. Pediatrics 1954;13:66-73.

11. Hrachovy RA, Frost JD Jr, Glaze DG. Hypsarrhythmia: variations on the theme. Epilepsia 1984;25:317-325.

12. Commission on Classification and Terminology of the International League Against Epilepsy. Proposal for revised classification of epilepsies and epileptic syndromes. Epilepsia 1989;30:389-399.

13. Jeavons PM, Bower BD. The natural history of infantile spasms. Arch Dis Child 1961;36:17-21.

14. Hrachovy RA, Glaze DG, Frost JD Jr. A retrospective study of spontaneous remission and long-term outcome in patients with infantile spasms. Epilepsia 1991;32:212-214.

15. Hattori H. Spontaneous remission of spasms in West syndromeimplications of viral infection. Brain Dev 2001;23:705-707.

16. Baram TZ, Mitchell WG, Tournay A, et al. High-dose corticotropin (ACTH) versus prednisone for infantile spasms: a prospective, randomized, blinded study. Pediatrics 1996;97:375-379.

17. Hrachovy RA, Frost JD Jr, Kellaway P, Zion TE. Double-blind study of ACTH vs prednisone therapy in infantile spasms. J Pediatr 1983;103: $641-645$.

18. Hrachovy RA, Frost JD Jr, Glaze DG. High-dose, long-duration versus low-dose, short-duration corticotropin therapy for infantile spasms. J Pediatr 1994;124:803-806.

19. Vigevano F, Cilio MR. Vigabatrin versus ACTH as first-line treatment for infantile spasms: a randomized, prospective study. Epilepsia 1997; 38:1270-1274

20. Yanagaki S, Oguni H, Hayashi K, et al. A comparative study of high dose and low-dose ACTH therapy for West syndrome. Brain Dev 1999; 21:461-467.

21. Hrachovy RA, Frost JD Jr, Kellaway P, et al. A controlled study of ACTH therapy in infantile spasms. Epilepsia 1980;21:631-636.

22. Kusse MC, Van Nieuwenhuizen O, Van Huffelen AC, et al. The effect on non-depot ACTH1-24 on infantile spasms. Dev Med Child Neurol 1993;35:1067-1073.

23. Lombroso CT. A prospective study of infantile spasms: clinical and therapeutic correlations. Epilepsia 1983;24:135-158.

24. Snead OC III, Benton JW Jr, Hosey LC, et al. Treatment of infantile spasms with high-dose ACTH: efficacy and plasma levels of ACTH and cortisol. Neurology 1989;39:1027-1031.

25. Cossette P, Riviello JJ, Carmant L. ACTH versus vigabatrin therapy in infantile spasms: a retrospective study. Neurology 1999;52:1691-1694.

26. Riikonen R, Simell O. Tuberous sclerosis and infantile spasms. Dev Med Child Neurol 1990;32:203-209.
27. Sher PK, Sheikh MR. Therapeutic efficacy of ACTH in symptomatic infantile spasms with hypsarrhythmia. Pediatr Neurol 1993;9:451-456

28. Snead OC III, Benton JW, Myers GJ. ACTH and prednisone in childhood seizure disorders. Neurology 1983;33:966-970.

29. Singer WD, Rabe EF, Haller JS. The effect of ACTH therapy upon infantile spasms. J Pediatr 1980;96:485-489.

30. Hrachovy RA, Frost JD Jr, Kellaway P, et al. A controlled study of prednisone therapy in infantile spasms. Epilepsia 1979;20:403-477.

31. Appleton RE, Peters ACB, Mumford JP, et al. Randomised, placebocontrolled study of vigabatrin as first-line treatment of infantile spasms. Epilepsia 1999;40:1627-1633.

32. Elterman RD, Shields WD, Mansfield KA, et al. Randomised trial of vigabatrin in patients with infantile spasms. Neurology 2001;57:14161421.

33. Fejerman N, Cersosimo R, Caraballo R, et al. Vigabatrin as a firstchoice drug in the treatment of West syndrome. J Child Neurol 2000;15: $161-165$.

34. Siemes H, Brandl U, Spohr H-L, et al. Long-term follow-up study of vigabatrin in pretreated children with West syndrome. Seizure 1998;7: 293-297.

35. Covanis A, Theodorou V, Lada C, et al. The first-line use of vigabatrin to achieve complete control of infantile spasms. J Epilepsy 1998;11:265269.

36. Vles JSH, Van der Heyden AMHG, Ghijs A, et al. Vigabatrin in the treatment of infantile spasms. Neuropediatrics 1993;24:230-231.

37. Wohlrab G, Boltshauser E, Schmitt B. Vigabatrin as a first-line drug in West syndrome: clinical and electroencephalographic outcome. Neuropediatrics 1998;29:133-136.

38. Granstrom M-L, Gaily E, Liukkonen E. Treatment of infantile spasms: results of a population-based study with vigabatrin as the first drug for spasms. Epilepsia 1999;40:950-957.

39. Tay SKH, Ong HT, Low PS. The use of vigabatrin in infantile spasms in Asian children. Ann Acad Med Singapore 2001;30:26-31.

40. Koo B. Vigabatrin in the treatment of infantile spasms. Pediatr Neurol 1999;20:106-110.

41. Kwong L. Vigabatrin as first line therapy in infantile spasms: review of seven patients. J Paediatr Child Health 1997;33:121-124.

42. Aicardi J, Hauser E, Steinbock H, et al. Vigabatrin as initial therapy for infantile spasms: a European retrospective survey. Epilepsia 1996; 37:638-642.

43. Wohlrab G, Boltshauser E, Schmitt B, et al. Visual field constriction is not limited to children treated with vigabatrin. Neuropediatrics 1999 ; 30:130-132.

44. Krauss GL, Johnson MA, Miller NR. Vigabatrin-associated retinal cone dysfunction. Electroretinogram and ophthalmologic findings. Neurology 1997;50:614-618.

45. Kalviainen R, Nousiainen I, Mantyjarvi M, et al. Initial vigabatrin monotherapy is associated with increased risk of visual field constric tion: a comparative follow up study with patients on initial carbamazepine therapy and healthy controls. Epilepsia 1998;39(suppl 6):D06.

46. Gross-Tsur V, Banin E, Shahar E, et al. Visual impairment in children with epilepsy treated with vigabatrin. Ann Neurol 2000;48:60-64.

47. Iannetti P, Spalice A, Perla FM, et al. Visual field constriction in children with epilepsy on vigabatrin treatment. Pediatrics 2000;106:838842.

48. Westall C, Buncic R, Logan W, et al. Longitudinal changes of ERGs in children on vigabatrin therapy. In: Sharpe J, ed. Neuro-ophthalmology in the new millennium. Proceedings of the INOS Meeting, Toronto, Canada. Engelwood, NJ: Medimond Medical Publications, 2001:29-34.

49. Fisher E, Siemes H, Pund R, et al. Valproate metabolites in serum and urine during antiepileptic therapy in children with infantile spasms: abnormal metabolite pattern associated with reversible hepatotoxicity. Epilepsia 1992;33:165-171.

50. Siemes H, Spohr HL, Michael T, et al. Therapy of infantile spasms with valproate: results of a prospective study. Epilepsia 1988;29:553-560.

51. Chamberlain MC. Nitrazepam for refractory infantile spasms and the Lennox-Gastaut syndrome. J Child Neurol 1996;11:31-34

52. Volzke E, Doose H, Stephan E. The treatment of infantile spasms and hypsarrhythmia with mogadon. Epilepsia 1967;8:64-70.

53. Ohtsuka Y, Matsuda M, Ogino T, et al. Treatment of the West syndrome with high-dose pyridoxal phosphate. Brain Dev 1987;9:418-421.

54. Pietz J, Benninger C, Schafer H, et al. Treatment of infantile spasms with high-dosage vitamin B6. Epilepsia 1993;34:757-763.

55. Suzuki Y, Nagai T, Ono J, et al. Zonisamide monotherapy in newly diagnosed infantile spasms. Epilepsia 1997;38:1035-1038.

56. Echenne B, Dulac O, Parayre-Chanez MJ, et al. Treatment of infantile spasms with intravenous gamma-globulins. Brain Dev 1991;13:313319 .

57. Yamamoto H, Asoh M, Murakami H, et al. Liposteroid (dexamethasone palmitate) therapy for West syndrome: a comparative study with ACTH therapy. Pediatr Neurol 1998;18:415-419.

58. Kossoff EH, Pyzik PL, McGrogan JR, et al. Efficacy of the ketogenic diet for infantile spasms. Pediatrics 2002;109:780-783. 
59. Matsumoto A, Kumagai T, Takeuchi T, et al. Factors influencing effectiveness of thyrotropin-releasing hormone therapy for severe epilepsy in childhood: significance of serum prolactin levels. Epilepsia 1989;30:45-49.

60. Glauser TA, Clark PO, Strawsburg R. A pilot study of topiramate in the treatment of infantile spasms. Epilepsia 1998;39:1324-1328.

61. Glauser TA, Clark PO, McGee K. Long-term response to topiramate in patients with West syndrome. Epilepsia 2000;41(suppl 4):S91-S94.

62. Zafeiriou DI, Kontopoulos EE, Tsikoulas IG. Adrenocorticotropic hormone and vigabatrin treatment of children with infantile spasms underlying cerebral palsy. Brain Dev 1996;18:450-452.

63. Schlumberger E, Dulac O. A simple effective and well-tolerated treatment regime for West syndrome. Dev Med Child Neurol 1994;36:863-872.
64. Dulac O, Chugani HT. Infantile spasms and West syndrome. Toronto: Saunders, 1994

65. Bachman DS. Spontaneous remission of infantile spasms with hypsarrhythmia. Arch Neurol 1981;38:785.

66. Glaze DG, Hrachovy RA, Frost JD Jr, et al. Prospective study of outcome of infants with infantile spasms treated during controlled studies of ACTH and prednisone. J Pediatr 1988;112:389-396.

67. Ohtsuka Y, Murashima I, Oka E, et al. Treatment and prognosis of infantile spasms. J Epilepsy 1994;7:279-284.

68. Holden KR, Clarke SL, Griesemer DA. Long-term outcomes of conventional therapy for infantile spasms. Seizure 1997;6:201-205. 


\section{Neurology}

\section{Practice Parameter: Medical Treatment of Infantile Spasms: Report of the American Academy of Neurology and the Child Neurology Society}

M. T. Mackay, S. K. Weiss, T. Adams-Webber, et al.

Neurology 2004;62;1668-1681

DOI 10.1212/01.WNL.0000127773.72699.C8

This information is current as of May 24, 2004

\section{Updated Information \& \\ Services}

Supplementary Material

References

Citations

Subspecialty Collections

Permissions \& Licensing

Reprints including high resolution figures, can be found at:

http://n.neurology.org/content/62/10/1668.full

Supplementary material can be found at: http://n.neurology.org/content/supp1/2005/07/27/62.10.1668.DC1 http://n.neurology.org/content/supp1/2005/07/27/62.10.1668.DC2

This article cites 61 articles, 4 of which you can access for free at: http://n.neurology.org/content/62/10/1668.full\#ref-list-1

This article has been cited by 12 HighWire-hosted articles: http://n.neurology.org/content/62/10/1668.full\#\#otherarticles

This article, along with others on similar topics, appears in the following collection(s):

All Epilepsy/Seizures

http://n.neurology.org/cgi/collection/all_epilepsy_seizures

Antiepileptic drugs

http://n.neurology.org/cgi/collection/antiepileptic_drugs

Infantile spasms

http://n.neurology.org/cgi/collection/infantile_spasms

Information about reproducing this article in parts (figures,tables) or in its entirety can be found online at:

http://www.neurology.org/about/about_the_journal\#permissions

Information about ordering reprints can be found online:

http://n.neurology.org/subscribers/advertise

Neurology ${ }^{\circledR}$ is the official journal of the American Academy of Neurology. Published continuously since 1951, it is now a weekly with 48 issues per year. Copyright. All rights reserved. Print ISSN: 0028-3878. Online ISSN: 1526-632X.

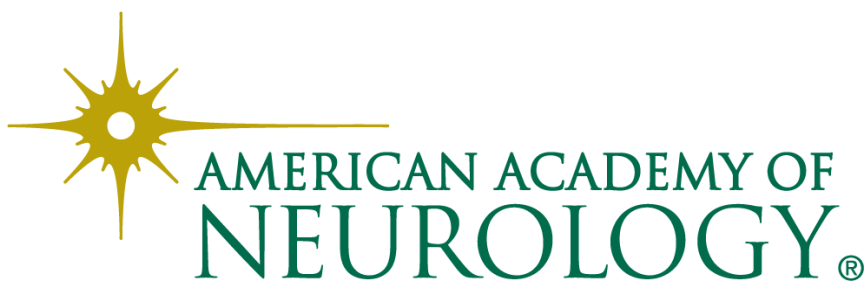

